\title{
PROGRAMA DE BOLSA DE INICIAÇÃO À DOCÊNCIA: TESES E DISSERTAÇÕES EM ANÁLISE.
}

\author{
Graciete Tozetto Goes ${ }^{1}$
}

\section{INTRODUÇÃO}

O Programa Institucional de Bolsas de Iniciação à Docência (PIBID), fomentado pela Coordenação de Aperfeiçoamento de Pessoal Nível Superior (CAPES) teve seu início em 2007 direcionado às Instituições Federais de Ensino Superior. O edital de 2009 abre para participação de Instituições Estaduais e Municipais e a partir do edital de 2011 também as Instituições de Ensino Superior privadas podem participar dos editais. Dessa forma, ampliouse significativamente $o$ número de Projetos Institucionais e bolsistas envolvidos. Segundo o relatório da Diretoria de Formação de Professores da Educação Básica (DEB) em 2014 são 284 as IES participantes do programa, envolvendo um total de 90.254 bolsistas. (Informações disponíveis em: http://www.capes.gov.br/educacao-basica/capespibid/relatorios-e-dados ).

O PIBID é criado em articulação com um conjunto de ações voltadas à formação de professores e à melhoria dos cursos de graduação em licenciatura. A CAPES a partir de 2007 passou a ter também como atribuição subsidiar o Ministério da Educação na formulação de políticas e no desenvolvimento de atividades de suporte à formação de profissionais de magistério para a educação básica e superior e para o desenvolvimento científico e tecnológico do País. Além do PIBID a CAPES formula outros programas voltados às Licenciaturas e a formação de professores, tais como: 0 Prodocência ${ }^{2}$, LIFE ${ }^{3}$, OBEDUC $^{4}$, PARFOR $^{5}$, Novos Talentos ${ }^{6}$, Competências

\footnotetext{
${ }^{1}$ Professora da Universidade Estadual de Ponta Grossa (UEPG). Doutoranda em Educação PPGE/UEPG. Membro do GEPPEA (Grupo de Estudos e Pesquisas em Política Educacional e Avaliação). E-mail: gtozetto@hotmail.com

${ }^{2}$ Programa de Consolidação das Licenciaturas ver: www.capes.gov.br

3 Programa de Apoio a Laboratórios Interdisciplinares de Formação de Educadores. Ver: www.capes.gov.br.

${ }^{4}$ O Programa Observatório da Educação - parceria entre a Capes, o INEP e a SECADI, ver: www.capes.gov.br.

${ }^{5}$ Plano Nacional de Formação de Professores da Educação Básica. Ver: www.capes.gov.br.

${ }^{6}$ Apoia a realização de atividades extracurriculares para professores e alunos da Educação Básica, visando disseminação do conhecimento científico e melhoria do ensino de ciências. Ver: www.capes.gov.br.
} 
Socioemocionais $^{7}$, e Programa STEM $^{8}$ e Projeto Água ${ }^{9}$. Todos estão organizados de forma a contribuir com a formação de professores e ações junto à Educação Básica.

A finalidade do PIBID é de apoiar a iniciação à docência dos estudantes das licenciaturas, de forma a aproximá-los das escolas de educação básica considerados espaços privilegiados de produção $\mathrm{e}$ apropriação de conhecimentos sobre a docência. Além disso, entre os objetivos do PIBID destaca-se a valorização da docência e a elevação do padrão de qualidade da educação básica por meio da melhor formação dos futuros professores. O PIBID envolve a vinculação da Universidade por meio de seus coordenadores institucionais, coordenadores de gestão e coordenadores de área com os professores da educação básica (professores supervisores) das escolas parceiras e os bolsistas de iniciação à docência que são os estudantes das licenciaturas. O surgimento do PIBID não se dá apenas em função do conjunto das políticas educacionais recentes. Muitos estudos e pesquisas ao longo dos últimos anos vêm denunciando a o excessivo distanciamento entre a formação recebida nos cursos de graduação em licenciatura e o contexto da educação básica. Considerando a repercussão desse programa foi realizada esta pesquisa teórica, de caráter bibliográfico articulado a uma análise de conteúdo dos resumos das teses e dissertações produzidas sobre o PIBID no período de 2012 a 2015.

\section{SOBRE A FORMAÇÃO INICIAL DE PROFESSORES}

A questão da formação de professores não é um tema novo e é quase um consenso que a qualidade da formação dos professores tem relação com a qualidade da educação a ser ofertada. Nas últimas décadas é possível perceber a significativa ampliação dos estudos sobre formação de professores (ANDRÉ et al., 1999).

\footnotetext{
7 Programa de Apoio à Formação de Profissionais no Campo das Competências Socioemocionais, ver: www.capes.gov.br.

${ }^{8}$ Programa de Cooperação Internacional STEM (Science, Technology, Engineering and Mathematics) em parceria com Conselho Britânico/Fundo Newton para a mobilidade e o intercâmbio de docentes. Ver: www.capes.gov.br.

${ }^{9}$ Programa de Apoio à Produção de Material Didático para a Educação Básica. Ver: www.capes.gov.br.
} 
Maues (2009) considera que a ampliação da preocupação com a formação de professores está também relacionada às novas formas de regulação do Estado e as necessidades de crescimento econômico. As políticas educacionais passam a colocar o professor como protagonista do processo educacional e das mudanças consideradas necessárias. A autora cita o documento "Educação e formação 2010", elaborado pela União Europeia em 2002. O referido documento aponta dentre os objetivos estratégicos "melhorar a qualidade e a eficácia dos sistemas de educação e de formação [...]" (MAUÉS, 2009, p. 478), desdobrado em outras colocações dentre as quais se destaca "melhorar a educação e a formação dos professores e formadores", como consequência amplia-se a preocupação com a formação inicial de professores. O Brasil, na esteira das ações de âmbito internacional, especialmente nas últimas décadas, evidencia maior centralidade na preocupação com a formação de professores. Estudos realizados por iniciativa do Ministério da Educação demonstram a falta de formação em nível superior de parte significativa dos docentes em serviço e a falta de professores de áreas como física, química e biologia. Partindo dessas influências e do pressuposto de que os professores não estão sendo formados com os saberes, conhecimentos e competências necessárias ao exercício da docência, um conjunto de políticas são implantadas.

Em 2002, as Diretrizes Curriculares Nacionais para a formação de professores (Resolução CNE 01/2002) entre outros aspectos, enfatiza a necessidade de um curso de formação de professores com identidade própria, deixando de ser um apêndice do bacharelado, além disso, inclui dentre os componentes curriculares as 400 horas da prática (CNE 02/2002) visando maior aproximação entre o contexto acadêmico e o contexto escolar.

O distanciamento entre a formação recebida no contexto universitário e a realidade escolar, ou a falta de ênfase dos currículos das licenciaturas em aspectos voltados à escola de educação básica é apresentada por diversos autores. Gatti e Nunes (2009, p.42) ao analisar as ementas dos cursos de licenciatura em Pedagogia constatam: "[...] que a escola é objeto quase ausente nas ementas, o que leva a pensar numa formação de caráter mais abstrato e pouco integrado ao contexto concreto onde o profissional professor vai atuar". As autoras destacam, ainda, a importância da formação 
inicial, pois compõe o desenvolvimento profissional contínuo que o professor deve ter. A formação inicial tem papel fundamental na qualidade dos docentes que passam por esse processo formativo e deveriam receber maior atenção das políticas educacionais de formação docente.

Em direção semelhante estão os estudos de Nóvoa (2004) enfatizando o espaço escolar como lugar de formação e desenvolvimento profissional do professor. Segundo o autor, nossa sociedade marcada pelo espetáculo, consumo, pela competição, pelo conhecimento, vem trazer novas exigências ao professor e a sua formação: organizacionais, relacionais, reflexivas e deliberativas. Tais exigências só poderão ser atendidas em práticas de formação localizadas na escola. Quando o papel da escola estava centrado na transmissão de conhecimentos, numa relação hierárquica daquele que sabe para quem não sabe, as exigências na formação eram diferentes. Nóvoa (2009, p. 203) apresenta cinco propostas de trabalho para inspirar os programas de formação de professores:

\begin{abstract}
Assumir uma forte componente práxica, centrada na aprendizagem dos alunos e no estudo de casos concretos, tendo como referência o trabalho escolar; Passar para «dentro» da profissão, baseando-se na aquisição de uma cultura profissional e concedendo aos professores mais experientes um papel central na formação dos mais jovens; Dedicar uma atenção especial às dimensões pessoais da profissão docente, trabalhando essa capacidade de relação e de comunicação que define o tacto pedagógico; Valorizar o trabalho em equipa e o exercício colectivo da profissão, reforçando a importância dos projectos educativos de escola; Caracterizar-se por um princípio de responsabilidade social, favorecendo a comunicação pública e a participação profissional no espaço público da educação.
\end{abstract}

As propostas de Nóvoa certamente influenciaram a área de formação de professores no Brasil e algumas dessas propostas parecem estar incorporadas a forma como o PIBID está organizado. Há uma ênfase na participação do acadêmico nas ações cotidianas da escola, na compreensão da cultura escola, além de, existir a supervisão (parceria) com o docente da educação básica já experiente. Nóvoa (2009, p.217) afirma:

No essencial, advogo uma formação de professores construída dentro da profissão, isto é, baseada numa combinação complexa de contributos científicos, pedagógicos e técnicos, mas que tem como âncora os próprios professores, sobretudo os professores mais experientes e reconhecidos. 
Imbernón (2010) também destaca a necessidade de repensar e reorganizar a formação inicial e continuada em articulação com o espaço onde os professores desenvolvem seu trabalho de forma que as necessidades formativas vão emergir do próprio contexto escolar.

Além das proposições na direção de uma maior proximidade com o contexto da escola, estudos sobre a formação inicial de professores trazem a discussão sobre os saberes (conhecimentos ou competências) presentes no trabalho do professor e em como articular esse conjunto de saberes de modo a qualificar a formação recebida. Nessa direção é possível citar os trabalhos de Tardif (2012) que aponta o saber do professor na intima relação com a escola e a sala de aula, além de destacar as características desse saber: plural, compósito, heterogêneo, o qual articula-se a um saber-fazer também bastante diferenciado. Para Tardif (2012) o saber docente é adquirido no decorrer de uma história de vida e de carreira profissional, por decorrência, os saberes a partir da experiência cotidiana também compõem o saber docente.

Almeida e Biajone (2007) destacam que o campo de pesquisas sobre o knowledge base ${ }^{10}$ surgem internacionalmente na década de 1980 e desde então tem se ampliado significativamente. Neste contexto também estão as produções de Lee S. Shulman, o qual distingue três categorias do knowledge base: conhecimento do conteúdo da matéria ensinada, conhecimento pedagógico da matéria e conhecimento curricular. (ALMEIDA; BIAJONE, 2007). As pesquisas de Shulman procuram investigar como os professores mobilizam o conhecimento dos conteúdos e os transformam nas situações de ensino. Tem buscado responder como se desenvolvem os conhecimentos de pedagogia e do conteúdo das matérias nas mentes dos novos professores, ou seja, como se dá a compreensão cognitiva dos conteúdos das matérias e as relações entre esses conteúdos e as atividades de ensino. (SHULMAN, 2005)

\footnotetext{
10 Knowledge base - pode ser traduzido como "base de conhecimento" - "[...] existe una "conocimiento base para la enseñanza" - esto es, un conjunto codificado o codificable de conocimientos, destrezas, comprensión y tecnología, de ética y disposición, de responsabilidad colectiva-, al igual que un medio para representarlo y comunicarlo." (SHULMAN, 2005, p. 5). Para o autor significa a base de conhecimentos que o professor necessita para atuar nas situações de ensino.
} 
No contexto das produções sobre a formação inicial de professores e, em especial, sobre os professores iniciantes o espanhol Carlos Marcelo Garcia, da Universidade de Sevilha tem apresentado estudos e pesquisas nas quais demonstra a importância do período inicial de inserção profissional, os primeiros anos de docência. Considera que neste período os professores ensinam, mas, ainda estão também num processo de aprendizagem. Esta fase deve ser e entendida como uma parte do contínuo desenvolvimento profissional do professor, por isso mereceria maior atenção dos gestores educacionais e das políticas públicas. Para o autor

El período de iniciación a la enseñanza representa el ritual que ha de permitir transmitir la cultura docente al profesor principiante (los conocimientos, modelos, valores y símbolos de la profesión), la integración de la cultura en la personalidad del propio profesor, así como la adaptación de éste al entorno social en que lleva a cabo su actividad docente. (MARCELO GARCIA, 1999, p. 105)

Além dos autores elencados muitos outros têm desenvolvido estudos e pesquisas voltados a compreender o processo de aprendizagem da docência e a constituição dos saberes docentes. É possível observar a crescente preocupação com a formação inicial de professores e seu processo de iniciação à docência. Nesse sentido, no Brasil, destaca-se o Programa Institucional de Bolsa de Iniciação à Docência (PIBID) com o propósito de qualificar os licenciandos e proporcionar a inserção no ambiente escolar ainda no contexto da graduação. Um conjunto de pesquisas foi produzido sobre o programa e na sequencia apresenta-se o mapeamento dessas produções.

\section{MAPEAMENTO DAS PRODUÇÕES}

Para este estudo foram levantados os trabalhos de teses e dissertações que abordam o Programa e nos quais seja no resumo, no título ou nas palavras-chave aparece a expressão PIBID. Para tanto foram utilizados 0 Bando de Teses e Dissertações da CAPES e a Biblioteca Digital de Teses e Dissertações (IBICT). Além desses bancos de dados, considerando a ampliação de estudos sobre o PIBID, foram acessados os sites dos Programas de Pós-Graduação em Educação e de Ensino das Universidades Federais, bem como das Universidades Estaduais do Paraná e PUCs da região Sul. Tal 
procedimento tem suas limitações considerando que nem sempre estão atualizados e disponíveis nas páginas dos programas todos os trabalhos produzidos e com fácil acesso. Assim, consideramos esse corpus de análise uma amostra das produções realizadas sobre o PIBID em termos de teses e dissertações.

Para organização dos trabalhos, primeiro foram classificados conforme a instituição e a região de origem, o ano de publicação, a autoria e o título do trabalho. Foram classificados também, de acordo com as áreas de licenciatura abordadas, bem como identificados os programas de pósgraduação e IES em que foram defendidos. Outro aspecto foi a verificação dos procedimentos de coleta e análise de dados mais utilizados nas pesquisas

A busca pelos trabalhos de teses e dissertações foi realizada a partir do descritor "PIBID" ou" Programa Institucional de Bolsa de Iniciação à Docência" encontradas no título, resumo e/ou palavras-chave. Feito o levantamento dos trabalhos realizou-se a leitura dos resumos e, em alguns casos, da introdução a fim de melhor compreender o foco da pesquisa. Entre teses e dissertações foram identificados 64 trabalhos, sendo 14 teses e 50 dissertações a partir do ano de 2012 até dezembro de 2015. Evidencia o crescimento do número de produções sobre o programa.

QUADRO 1 - Datas das produções

\begin{tabular}{|l|l|l|l|l|l|}
\hline Tipo de produção & $\mathbf{2 0 1 2}$ & $\mathbf{2 0 1 3}$ & $\mathbf{2 0 1 4}$ & $\mathbf{2 0 1 5}$ & TOTAL \\
\hline Tese & 1 & 4 & 3 & 6 & 14 \\
\hline Dissertação & 15 & 8 & 17 & 10 & 50 \\
\hline
\end{tabular}

Fonte: a autora.

No ano de 2012 foi identificada mais uma tese que trazia a expressão PIBID no resumo, no entanto, foi excluída da análise porque o foco era o ENEM e apenas indicava que uma das instituições investigadas contava com um grupo do PIBID.

Quanto à região onde os trabalhos foram produzidos nota-se que a maioria está nas regiões sul e sudeste. Tal concentração pode ser explicada pelo número de programas de pós-graduação em educação ou em ensino, localizados nessas regiões. 
QUADRO 2 - Região das produções

\begin{tabular}{|l|l|l|l|l|l|}
\hline Tipo de produção & Região Norte & Região Nordeste & Região Centro Oeste & Região Sudeste & Região Sul \\
\hline Tese & - & - & 1 & 7 & 6 \\
\hline Dissertação & - & 2 & 4 & 18 & 26 \\
\hline Total & - & $\mathbf{2}$ & $\mathbf{5}$ & $\mathbf{2 5}$ & $\mathbf{3 2}$ \\
\hline
\end{tabular}

Fonte: a autora.

Considerando que o PIBID abrange as diferentes licenciaturas, no quadro seguinte é possível identificar as áreas com maior número de produções: Matemática, Química, Ciências Biológicas e Pedagogia.

QUADRO 3 - Áreas analisadas nas Produções

\begin{tabular}{|c|c|c|c|}
\hline Área & Tese & Dissertação & Total \\
\hline Matemática & 1 & 9 & 10 \\
\hline Química & 3 & 6 & 9 \\
\hline Biologia / Ciências Biológicas & 2 & 6 & 8 \\
\hline Pedagogia & 3 & 3 & 6 \\
\hline Matemática e Física & - & 1 & 1 \\
\hline Física / Química / Biologia & - & 2 & 2 \\
\hline Física & 1 & 4 & 5 \\
\hline Física/Matemática/Química/Letras-Inglês & 1 & - & 1 \\
\hline Educação Física & 1 & 2 & 3 \\
\hline Música & 1 & 1 & 2 \\
\hline Inglês & - & 2 & 2 \\
\hline Filosofia & - & 2 & 2 \\
\hline História & - & 1 & 1 \\
\hline Artes Visuais & - & 1 & 1 \\
\hline Língua Portuguesa & - & 1 & 1 \\
\hline Geografia & - & 1 & 1 \\
\hline Projeto Interdisciplinar & 1 & - & 1 \\
\hline Todo o programa & - & 1 & 1 \\
\hline Coordenadores de área & - & 1 & 1 \\
\hline Professores supervisores & - & 3 & 3 \\
\hline Escola Educação Básica & - & 2 & 2 \\
\hline Expressões faciais & - & 1 & 1 \\
\hline Total & 14 & 50 & 64 \\
\hline
\end{tabular}

Fonte: a autora.

Os trabalhos foram defendidos predominantemente nos

Programas de Pós-graduação em Educação embora haja significativo número de trabalhos em outros programas. Em termos percentuais $50 \%$ dos trabalhos 
foram realizados nos PPGEs e os outros 50\% em Programas de áreas específicas, conforme pode ser observado no quadro a seguir.

QUADRO 4 - Programas de Pós-Graduação onde os trabalhos foram apresentados

\begin{tabular}{|l|l|l|l|}
\hline PROGRAMA & Tese & Dissertação & Total \\
\hline PPG Educação & 9 & 23 & 32 \\
\hline PPG Química & 2 & 1 & 3 \\
\hline PPG Ciências e Educação Matemática & 2 & 8 & 10 \\
\hline PPG Ciências, Química da Vida e Saúde & 1 & 1 & 2 \\
\hline PPG em Ciências e em Matemática & - & 5 & 5 \\
\hline PPG em Ensino de Matemática & - & 1 & 1 \\
\hline PPG em Educação Matemática & - & 3 & 3 \\
\hline PPG em Estudos da Linguagem & - & 2 & 2 \\
\hline PPG em Ensino de Ciências Naturais & - & 1 & 1 \\
\hline PPG Ensino de Ciências & - & 1 & 1 \\
\hline PPG em Ciências do Movimento Humano & - & 1 & 1 \\
\hline PPG Educação Escolar & - & 2 & 2 \\
\hline PPG Educação Física & - & 1 & 1 \\
\hline Total & $\mathbf{1 4}$ & $\mathbf{5 0}$ & $\mathbf{6 4}$ \\
\hline
\end{tabular}

Fonte: a autora.

Houve um número significativo de trabalhos nos programas de pós-graduação de áreas específicas, o que parece indicar a ampliação do interesse pela formação de professores nesses programas.

\section{ANÁLISE DOS RESUMOS}

As produções de teses e dissertações apresentam um delineamento metodológico mais elaborado e foi possível identificar por meio dos resumos e da introdução dos trabalhos, os principais procedimentos de coleta e análise dos dados presentes nas pesquisas sobre o PIBID. Nem sempre nos resumos estão explicitados com clareza o objetivo do trabalho, o tipo de pesquisa realizada, os procedimentos de coleta e análise de dados, bem como, os principais resultados a que se chegou. No quadro seguinte é possível identificar os principais instrumentos/procedimentos para a coleta de dados. Claramente observa-se que a entrevista (em suas diferentes tipologias) é o procedimento mais utilizado, seguido da análise documental, dos questionários e da observação. Muitos trabalhos apresentam a utilização de 
mais de um procedimento/instrumento para a coleta de dados. Mesmo assim, fica clara a preferência por procedimentos que valorizam o discurso dos sujeitos e permitem analisar o programa a partir de certa interação com os participantes do mesmo.

QUADRO 5 - Procedimentos/instrumentos de coleta de dados

\begin{tabular}{|l|l|l|l|}
\hline Tipologia & Tese & Dissertação & Total \\
\hline Entrevistas semi estruturadas/ semi abertas/ entrevista aberta/ entrevista estruturada & 8 & 31 & 39 \\
\hline Análise documental / documentos & 3 & 13 & 16 \\
\hline Questionários & 1 & 13 & 14 \\
\hline $\begin{array}{l}\text { Observação sistemática/ Obs. participante/ Obs. de campo/ Acompanhamento de } \\
\text { atividades }\end{array}$ & 5 & 7 & 12 \\
\hline Histórias escritas/ Narrativas escritas/ narrativas autobiográficas/ memorial descritivo & 3 & 5 & 8 \\
\hline Diário de campo/ Diário de pesquisa / Notas de campo / Diário de bordo & 3 & 4 & 7 \\
\hline Relatórios anuais / relatórios diversos & 1 & 6 & 7 \\
\hline Portfólios/ escritos reflexivos & 2 & 3 & 5 \\
\hline Grupos focais & 3 & 2 & 5 \\
\hline Registros de grupos de estudo / de reuniões & - & 4 & 4 \\
\hline Pesquisa documental e bibliográfica & - & 4 & 4 \\
\hline Fotografias / filmagens / gravações & - & 3 & 3 \\
\hline Diários de aula /Planos de aula & - & 2 & 2 \\
\hline Roteiros de análise textual & - & 1 & 1 \\
\hline Produções de história em quadrinhos & - & 1 & 1 \\
\hline Apresentações em eventos & - & 1 & 1 \\
\hline Depoimentos & 1 & - & 1 \\
\hline Fone: a a & & \\
\hline
\end{tabular}

Fonte: a autora.

A maioria dos resumos não detalha o tipo de pesquisa definido para o estudo. Os estudos que se definem como de abordagem qualitativa ${ }^{11}$, em geral, apresentam-se como estudos de caso ou estudo de caso etnográfico. Apenas um estudo apresentou-se com abordagem quali-quantitativa ${ }^{12}$. Observa-se a ausência de estudos mais abrangentes (nacionais, regionais) apresentando outros indicadores de caráter quantitativo.

QUADRO 6 - Abordagem / tipo de pesquisa

\begin{tabular}{|l|l|l|l|}
\hline Tipologia & Teses & Dissertações & Total \\
\hline
\end{tabular}

\footnotetext{
${ }_{11}^{11}$ Abordagem qualitativa ver: CHIZZOTTI, 2003.

12 Abordagem quali-quantitativa - não considera incompatíveis as abordagens quantitativa e qualitativa. Dessa forma, articula dados quantitativos e análises qualitativas.
} 


\begin{tabular}{|l|l|l|l|}
\hline Abordagem qualitativa & - & 20 & 20 \\
\hline Abordagem quali-quantitiativa & - & 1 & 1 \\
\hline Estudo de caso / estudo de caso etnográfico & 1 & 14 & 15 \\
\hline Pesquisa exploratório descritiva & - & 3 & 3 \\
\hline Pesquisa descritivo-explicativa & - & 1 & 1 \\
\hline Pesquisa investigação-ação emancipatório -colaborativa & - & 1 & 1 \\
\hline Pesquisa participante & - & 1 & 1 \\
\hline
\end{tabular}

Fonte: a autora.

Os procedimentos para a análise dos dados privilegiam a análise de conteúdo $^{13}$, a análise textual discursiva ${ }^{14}$ e a análise crítica do discurso ${ }^{15}$. Tal prevalência está articulada aos procedimentos de coleta de dados que privilegiam a expressão dos sujeitos sobre o tema, como no caso da utilização das entrevistas e mesmo das narrativas exigindo formas de análise que permitam compreender seu significado e obter inferências a partir deles.

QUADRO 7 - Procedimentos para análise de dados

\begin{tabular}{|l|l|l|l|}
\hline Tipologia & Teses & Dissertações & Total \\
\hline Análise de conteúdo & 3 & 9 & 12 \\
\hline Análise textual discursiva/ Análise crítica do discurso/ Análise discursiva & 3 & 9 & 12 \\
\hline Análise da Ação Docente em Sala de Aula & 1 & 1 & 1 \\
\hline Focos de aprendizagem docente (FAD) & - & 2 & 2 \\
\hline Categorias emergentes dos dados & 2 & - & 2 \\
\hline Eixos temáticos & 1 & - & 1 \\
\hline Análise do discurso em Foucault & - & 1 & 1 \\
\hline
\end{tabular}

Fonte: a autora.

Considerando as inúmeras possibilidades de enfoque, realizou-se a leitura dos resumos procurando identificar qual o principal foco do trabalho. Tal procedimento se fez necessário porque em muitos casos o descritor "PIBID" aparece no resumo ou nas palavras-chave e o Programa ou os participantes do programa são o "lócus" da pesquisa ou os "sujeitos" sem que se faça discussão mais aprofundada sobre o programa em si e seus objetivos. $O$ quadro seguinte apresenta em que os trabalhos produzidos centram suas análises.

\footnotetext{
${ }^{13}$ Análise de conteúdo ver: BARDIN, 1977.

${ }^{14}$ Análise textual discursiva ver: MORAES; GALIAZZI, 2006.

${ }^{15}$ Análise crítica do discurso ver: FAIRCLOUGH, 2012.
} 


\section{QUADRO 8 - Foco dos trabalhos analisados}

\begin{tabular}{|c|c|c|c|c|c|}
\hline n. & FOCO DO TRABALHO & Tese & Dissertação & Total & $\%$ \\
\hline 1 & $\begin{array}{l}\text { Uma ou mais áreas específicas do PIBID (determinada } \\
\text { licenciatura) - contribuições, limites, influência, práticas } \\
\text { de formação. }\end{array}$ & T6 & $\begin{array}{l}\text { D1 D2 D7 D9 D10 D11 } \\
\text { D21 D22 D26 D39 D41 } \\
\text { D42 D43 }\end{array}$ & 14 & 21,9 \\
\hline 2 & Bolsista (aprendizagem/aprendizagem da docência) & $\begin{array}{l}\text { T2 } \\
\text { T1 } 7 \\
\text { T1 }\end{array}$ & $\begin{array}{l}\text { D12 D16 D17 D19 } \\
\text { D20 D29 D31 D35 }\end{array}$ & 12 & 18,7 \\
\hline 3 & $\begin{array}{l}\text { Determinadas metodologias/estratégias utilizadas no } \\
\text { PIBID }\end{array}$ & T1 & $\begin{array}{l}\text { D3 D13 D14 D15 D44 } \\
\text { D45 D47 D48 }\end{array}$ & 9 & 14,1 \\
\hline 4 & Professor supervisor & T4 T14 & D27 D30 D33 D37 D49 & 7 & 10,9 \\
\hline 5 & $\begin{array}{l}\text { Prática de ensino/prática docente/constituição da } \\
\text { docência }\end{array}$ & T3 T10 & D8 D32 D40 D46 & 6 & 9,4 \\
\hline 6 & Egressos do programa & - & D24 D25 D36 D50 & 4 & 6,3 \\
\hline 7 & $\begin{array}{l}\text { Identidade profissional/ } \quad \text { identidade } \\
\text { profissionallidade docente }\end{array}$ & T12 T13 & D6 & 3 & 4,7 \\
\hline 8 & O conjunto do Programa (contribuições, limites) & T5 T8 & - & 2 & 3,1 \\
\hline 9 & Tema específico (sexualidade, pensamento crítico) & - & D23 D28 & 2 & 3,1 \\
\hline 10 & Relação escola/universidade & - & D5 D38 & 2 & 3,1 \\
\hline 11 & $\begin{array}{l}\text { OUTROS - Relação professor/aluno; Coordenadores de } \\
\text { área / Escola de Educação Básica (mudanças/ações) }\end{array}$ & - & D18 D34 D4 & 3 & 4,7 \\
\hline
\end{tabular}

Fonte: a autora.

O conjunto maior de trabalhos trata das contribuições e limitações do programa para uma ou mais licenciaturas no contexto de determinada instituição. Em um dos trabalhos é analisada a contribuição do programa para o desenvolvimento profissional dos acadêmicos da licenciatura em química de várias instituições nas cinco regiões brasileiras. Os objetivos estão centrados em identificar mudanças, contribuições, influências do PIBID na formação e nos próprios cursos de licenciatura da instituição.

Num segundo conjunto de trabalhos observa-se a ênfase no processo de aprendizagem dos bolsistas, evidenciado em objetivo tais como:

Apresentar as nossas compreensões das relações estabelecidas com o ensinar, com o saber e com o aprender que os estudantes desenvolveram durante os dois anos de participação nesse programa, e, também, falar sobre a aprendizagem da docência no contexto PIBID. (T2)

A forma como o programa é desenvolvido e as metodologias utilizadas também são foco dos trabalhos produzidos. Neste caso, a intenção é analisar a efetividade e os resultados da utilização de determinadas 
metodologias de ensino pelos bolsistas do PIBID, ou, ainda, analisar a utilização de determinadas estratégias de formação utilizadas no projeto institucional do programa.

Um número significativo de trabalhos procura analisar o papel dos professores supervisores (da Educação Básica). Alguns dão ênfase ao papel formativo desempenhado pelos professores supervisores, outros discutem a formação continuada e o desenvolvimento profissional desses professores como sendo também um dos objetivos do PIBID. O objetivo formulado expressa essa intenção: "Analisar as contribuições do PIBID para o desenvolvimento profissional de professores-supervisores e a possibilidade das ações e referenciais teóricos deste constituírem-se em um projeto de formação continuada em serviço". (D27)

Os trabalhos identificados demonstram a diversidade de possibilidades de análises que o programa permite. Um conjunto deles trata da prática docente, da prática de ensino e sua relação com a formação recebida no Programa. Foram identificados quatro trabalhos, todos de dissertação, que tem como principais sujeitos os egressos do programa. Os estudos buscam apresentar os possíveis impactos do programa na formação dos participantes do programa. Foram considerados egressos em alguns casos, aqueles que participaram do mesmo por determinado período, independente de terem concluído a graduação e em outros casos são considerados egressos do programa e da licenciatura (formados). "Compreender o processo de iniciação à docência dos egressos do PIBID, área de matemática, identificando suas contribuições e limites" (D 24).

Os trabalhos agrupados com os demais focos tem um número menos expressivo. Interessante notar que apenas dois trabalhos (teses) realizaram o estudo do Programa como um todo em determinada instituição $(T 5, T 8)$ apontando para a necessidade de processos de avaliação institucional dos programas. Dois trabalhos tratam de temáticas bastante específicas (sexualidade, desenvolvimento do pensamento crítico) desenvolvidas no âmbito do PIBID de determinada licenciatura (D23 e D28). Dois trabalhos analisam a relação da universidade com a escola de educação básica e as possíveis mudanças nessas instituições a partir da implantação do PIBID. Embora o objetivo central do programa seja a iniciação à docência dos 
acadêmicos das licenciaturas é muito importante considerar que aspectos afetam o cotidiano da escola, a presença dos bolsistas traz novos elementos para a organização da escola, para a utilização de novas metodologias. No último foco foram agrupados trabalhos que não se enquadravam nos aspectos focalizados anteriormente. É o caso do trabalho que analisa a relação professor-aluno a partir das expressões faciais (D 18), do trabalho que analisa a influência do PIBID na formação dos coordenadores de área (D 34) e do trabalho que analisa a repercussão na escola das atividades de determinado subprojeto (D4).

Nessa direção o programa apresenta-se como importante estratégia de formação que desenvolve atividades coletivas, colaborativas, com destaque para o trabalho em grupo e valorização do ensino. A maioria dos trabalhos aponta para a importância do programa e os desafios da formação de professores. A centralidade do professor vem ao encontro das tendências atuais de formação de professores voltadas a estabelecer uma forte relação com a escola e com a docência na direção de "praticar", inserir-se na cultura escolar e desenvolver um processo de problematização das situações vividas no contexto escolar (NÓVOA, 2004, 2009; GATTI e NUNES, 2009). Cabe destacar que essa inserção e prática podem assumir diferentes características, tanto numa perspectiva mais crítica quanto numa perspectiva mais técnica. De qualquer forma a proposta desenhada pela instituição universitária e a concepção de formação defendida é que contribuirão para os resultados e impactos do programa.

\section{CONSIDERAÇÕES FINAIS}

Tendo como corpus de análise as teses e dissertações foi possível apresentar as produções sobre o PIBID. Os trabalhos identificados oferecem possibilidades de compreender os diferentes enfoques e ênfases no estudo do programa.

O conjunto das produções analisadas revela aspectos importantes tais como: as pesquisas realizadas de 2012 a 2015 predominam nas regiões Sul e Sudeste; as áreas com maior número de trabalhos produzidos foram de Matemática, Química e Ciências Biológicas; os trabalhos focalizam diferentes 
aspectos do programa, principalmente a contribuição do mesmo em subprojetos ou áreas específicas da formação.

Ao colocar a centralidade da docência num programa como o PIBID surgem inúmeras possibilidades investigativas como foi possível observar nas produções analisadas. Desde a perspectiva de um programa situado no âmbito de uma política educacional mais ampla, influenciada por movimentos nacionais e internacionais até o espaço micro social da sala de aula e das práticas desenvolvidas pelos diferentes sujeitos participantes do programa: bolsistas, professores supervisores, coordenadores. Também permite análises mais aprofundadas sobre a aprendizagem da docência, os saberes constitutivos da docência e que contribuem para o repensar da formação desenvolvida no interior dos cursos de licenciatura.

\section{REFERÊNCIAS}

BRASIL. Resolução CNE/CP no 01, de 18 de fevereiro de 2002: Institui as diretrizes curriculares nacionais para a formação de professores da educação básica, em nível superior, curso de licenciatura, de graduação plena. Brasília, DF, 2002a.

BRASIL. Resolução CNE/CP no 02, de 19 de fevereiro de 2002: Institui a duração e carga horária dos cursos de licenciatura, de graduação plena, de formação de professores da educação básica em nível superior. Brasília, DF, 2002b.

BARDIN, L. Análise de conteúdo. Lisboa : Edições 70, 1977. Disponível em: <http://pt.slideshare.net/RonanTocafundo/bardin-laurence-anlise-decontedo?related=>1 Acesso em: 19 jan. 2016.

CHIZZOTTI, A. A pesquisa qualitativa em ciências humanas e sociais: evolução e desafios. Revista Portuguesa de Educação, Braga, v.16, n.2, p.221-236, 2003.

FAIRCLOUGH, N. Análise crítica do discurso como método em pesquisa social científica. Linha D’Água, v.25, n. 2, p. 307-329, 2012. Disponível em: http://www.revistas.usp.br/linhadagua/article/view/47728/51460 Acesso em: 18 jan. 2016.

GATTI, B.A.; NUNES, M.M.R. Formação de professores para o ensino fundamental: estudo de currículos das licenciaturas em Pedagogia, Língua Portuguesa, Matemática e Ciências Biológicas. São Paulo : FCC, 2009.

IMBERNÓN, F. Formação docente e profissional: formar-se para a mudança e a incerteza. 8. ed. São Paulo : Cortez, 2010. 
MAUÉS, O. Regulação educacional, formação e trabalho docente. Estudos em Avaliação Educacional, São Paulo, v.20, n.44, p. 473-492, 2009.

MARCELO GARCIA, C. Estudio sobre estrategias de inserción profesional en Europa. Revista Iberoamericana de Educación, n.19, p.101-143, jan./abr. 1999. Disponível em: http://www.rieoei.org/oeivirt/rie19.htm Acesso em: 09 out. 2015.

MORAES, R.; GALIAZZI, M.do C. Análise textual discursiva: processo reconstrutivo de múltiplas faces. Ciência e Educação, Bauru, v. 12, n.1, p.117128, 2006. Disponível em: http://www.scielo.br/pdf/ciedu/v12n1/08.pdf Acesso em: 19 jan. 2016.

NOVOA, A. Novas disposições dos professores. A escola como lugar da formação. Correio da Educação: o semanário dos professores. N. 47, 16 fev. 2004. Disponível em: <http://hdl.handle.net/10451/685> Acesso em: 09 out. 2015.

NOVOA, A. Para uma formação de professores construída dentro da profissão. Revista Educacion, Madrid, n. 350, p.203-218, set./dec. 2009.

SHULMAN, L. S. Conocimiento y enseñanza: fundamentos de la nueva reforma. Profesorado. Revista de currículum y formación del profesorado, v.9, n.2, p. $1-30, \quad 2005 . \quad$ Disponível em: http://www.ugr.es/local/recfpro/Rev92ART1.pdf Acesso em: 26 jan. 2016.

TARDIF, M. Saberes docentes e formação profissional. 14.ed. Petrópolis : Vozes, 2012. 